Adapting to and Coping with the Threat and Impacts of Climate Change

\author{
Joseph P. Reser \\ Griffith University, Queensland, Australia \\ and Janet K. Swim \\ Pennsylvania State University
}

Article manuscript submitted to the American Psychologist for inclusion in proposed special edition focus on Psychology and Climate Change, 15 July 2010

Resubmission with amendments on 30 November 2010 


\begin{abstract}
The article addresses the nature and challenge of adaptation in the context of global climate change. The complexity of 'climate change' as threat, environmental stressor, risk domain, and impacting processes with dramatic environmental and human consequences requires a synthesis of perspectives and models from diverse areas of psychology to adequately communicate and explain how a more psychological framing of the 'human dimensions of global environmental change' can greatly inform and enhance effective and collaborative climate change adaptation and mitigation policies and research. An integrative framework is provided which identifies and considers important mediating and moderating parameters and processes relating to climate change adaptation, with particular emphasis given to environmental stress and stress and coping perspectives. This psychological perspective on climate change adaptation highlights crucial but neglected aspects of adaptation in the climate change science arena. Of particular importance are intra-individual and social psychological adaptation processes which powerfully mediate public risk perceptions and understandings, effective coping responses and resilience, overt behavioral adjustment and change, and psychological and social impacts. This psychological window on climate change adaptation is arguably indispensable to genuinely multidisciplinary and interdisciplinary research and policy initiatives addressing the impacts of climate change.
\end{abstract}

Keywords: Climate change, psychological adaptation, environmental stress, stress and coping, psychologically significant behaviour 


\section{Adapting to and Coping with the Threat and Impacts of Climate Change}

Yet, even with the most ambitious mitigation actions, the inertia of the system will ensure that the impacts of climate change will continue for centuries, if not beyond a millennium. Knowledge of impacts and the manner in which they would grow over time is therefore critical to the development of capacity and measures for adaptation to climate change. (Pachauri, 2009, xiv)

Adaptation to the threat and rapidly unfolding impacts of climate change has become a pressing and urgent issue, given the alarming rapidity with which predicted climate changes are taking place. The question of 'what can be done' to address the global - and very human - crisis which is now upon us is refocusing world attention on climate change adaptation (Pielke, et al., 2007). The threat of what will be very likely consequences of climate change, have been given palpable reality by extensive media coverage, at times apocalyptic in nature (e.g., Smith \& Joffe, 2009). Addressing the challenges of adapting to climate change is important not only to ensure the safety and security of human and nonhuman populations in many regions of the world, but to ensure that immediate and pressing needs do not derail still vital national and international climate change mitigation policies.

\section{Defining climate change adaptation}

In this article 'climate change’ refers to the threat and unfolding environmental impacts of current climate change, with a clear understanding that what is typically referred to in everyday conversation and with respect to climate change adaptation are the threatened environmental and human consequences of climate change, not changes in global climate patterns. 'Climate change’ constitutes a complex risk domain, attitudinal object, and social representation, with respect to a phenomenon which is as much a social phenomenon as it is a physical phenomenon (e.g., Grauman \& Kruse, 1990; Hulme, 2009; Wagner \& Hayes, 2005). 
The Intergovernmental Panel on Climate Change (IPCC) defines adaptation as "adjustment in natural or human systems in response to actual or expected climatic stimuli or their effects, which moderates harm or exploits beneficial opportunities” (IPCC, 2007b). According to this IPCC definition, adaptation may include responses made in anticipation of climate change impacts, responses that are a result of deliberate policy decisions based upon awareness of current or upcoming changes, and “autonomous" or "spontaneous” responses that represent unplanned responses "triggered by ecological changes in natural systems and by market or welfare changes in human systems.”. Adaptation in this climate change science context often refers to structural changes, such as building more 'resistant' human settlements and infrastructure or providing ways to ensure adequate and sustainable water and food availability and micro and macro human system adjustments, such as those relating to households, communities, institutions, and regional, national, and global governance structures and policies.

A psychological perspective on adaptation includes many of these human setting and system considerations, and both anticipated and reactive responses to climate change, but goes beyond these in encompassing human experience and psychological well being. Psychological forms of adaptation are very infrequently referenced or addressed in the current climate change science adaptation literature (e.g., IPCC, 2007; Leary et al., 2008; Schipper \& Burton, 2009). Adaptation as a construct and foundational process has been used nonetheless in a rich and convergent variety of ways in psychology and in the health and social sciences generally (e.g., Lazarus, 1991; Martin, 1964; White, 1974). Like evolutionary biologists, evolutionary psychologists have used adaptation to refer to genotypic changes that have increased reproductive success and survival, including hardwired behavioral adaptations. A classic and biological system-based use of adaptation refers to specific psychophysiological responses, such as sensory habituation to changing stimuli (e.g., noise, 
temperature, or amount of light). But adaptation also encompasses the diverse types of coping responses individuals can make to changes in their physical and social environments, including natural disasters and the ongoing threat of war and terror (e.g., Bell et al., 2001; Holahan, 1982; Marshall et al., 2007). Adaptation is also commonly used to refer to intraindividual and extra-individual processes and actions that involve, for instance, accommodating, assimilating, or adjusting to various contexts and new or difficult life circumstances (e.g., work situations, new cultures, globalization, adoption, chronic illness).

What is distinctive about psychology's use of the term adaptation, particularly when used to refer to adaptation processes, is that it encompasses and integrates both intraindividual parameters and processes (e.g., appraisals of situations, affective responses, cognitive analysis and reframing, disengagement, defensive responses, and emotion regulation) as well as extra-individual social and situation processes (e.g., proximity and exposure, collective sense making, social comparison, social construction, social amplification of risk, and collective efficacy) that influence how individuals and communities respond to challenging circumstances. This more encompassing set of meanings and contexts for adaptation is integral to and greatly informs both 'environmental stress' and 'stress and coping' approaches to understanding people’s responses to difficult and taxing situations (e.g., Evans \& Stecker, 2004; Stokols, 1978).

An environmental stress perspective on the adaptation demands of global climate provides a particularly appropriate framework for considering adaptation in the context of climate change (e.g., Bell et al., 2001; Evans \& Cohen, 1991, Evans \& Stecker, 2004). This framework brings environmental and human ecological perspectives to the complex phenomenon of climate change. It encompasses the requisite multiple levels of analysis needed to adequately frame the adaptation challenges of dramatic climate change impacts and to strategically address planning considerations and interventions enhancing individual and 
community adaptations (e.g., Winkel, Saegert \& Evans, 2009). This perspective encompasses and articulates with research on environmental perception and evaluation, risk appraisal, communication, and management, and disaster preparedness, response, and recovery (e.g., Reyes \& Jacobs, 2006). Disaster research is particularly germane because many of the projected impacts of climate change will take the form of acute and longer term natural disasters. Finally, an environmental stress perspective also informs and complements research on stress and coping, which itself examines and addresses individual level psychological processes as well as community level coping mechanisms (e.g., Baum \& Fleming 1993; Holahan \& Wandersman, 1991; Lazarus \& Cohen, 1977).

\section{An illustrative synthesis model}

There exist many models of environmental stress, and stress and coping, but for the purpose of providing a synthetic model that might more usefully articulate with the schemas and models of the IPCC and climate change scientists, while underscoring the psychological, we have developed a further organizational framework for a number of the considerations which follow in this article (see Figure 1). This derives from related and convergent psychological models (e.g., environmental stress, adaptation, stress and coping models, protection motivation theory, and the health belief model (e.g., Glanz, Rimer, \& Lewis, 2002; Lazarus \& Folkman, 1984; Rogers \& Prentice-Dunn, 1997; Vaughn, 1993). We first provide an overview of the model and then describe specific elements of the model as they might apply to climate change adaptation.

The initiators of the adaptation process, noted on the far left of the figure, are conceptualized as stressors, and in this context they include direct and indirect experiences with the threat and impacts of climate change. Initial responses to these threatening changes, 'impacts', or conditions include cognitive responses in the form of appraisals of the impacts relative to resources (threat appraisals), appraisals of possible responses (coping appraisals), 
and simultaneous emotion-based and cultural meaning system informed interpretative and motivational responses and processes. For instance, individuals who reside in a coastal community will assess the probability and extent to which they and their family will be affected by rising sea levels and whether they have resources to respond to rising sea levels (threat appraisals). They may also assess what they think they could or should do about rising sea levels and whether what they might do would make a difference (coping appraisal). Their risk perceptions and coping appraisals though may be equally influenced by the nature of climate change as a risk domain, the possible symbolic import, dread, and uncertainty associated with such a catastrophic scenario, prior personal or vicarious experience with inundation or dramatic environmental change or displacement, and protection motivation and psychological distancing mechanisms to counter anxieties, concerns, and possible felt responsibility for the very changed world which climate change may well usher in. (e.g., Slovic et al., 2004; Vaughan, 1993; Weber, 2006).

These initial responses influence each other as well as the selection of intra-individual and behavioural responses at both the individual and community level, which in turn mediate individual and community impacts. For instance, greater perceived threat can lead to more worry. Together these responses can lead to intra-individual emotion regulation and defensive responses or participation in civic action to encourage one's community to develop protective measures to address rising sea levels (behavioral response). Different coping responses result in and themselves mediate different types of impacts on individuals and communities.

Doherty \& Clayton (2010) in this issue address the psychological impacts of climate change. These psychological responses feed back into appraisals, affective responses, attributions, and motivations already mentioned. As the example illustrates, adaptation processes can change over time, for instance, as particular problems are addressed or as coping resources diminish (e.g., Lepore \& Evans, 1996). Finally, many moderators can exercise influence at 
each stage in the model and examples are listed at the bottom of the figure. For instance, individuals and communities with fewer resources and institutionalised histories of powerlessness and disadvantage are likely to be more vulnerable and less resilient to climate changes due to, for instance, the inability to engage in effective coping responses (e.g., Cutter, 2003; Norris et al., 2008).

\section{Climate change threat and environmental impacts and change as stressors}

In what follows we extrapolate from research on environmental stress and stress and coping to the context of global and local climate change, and refer to research from convergent areas of disaster preparedness and response, risk perception and appraisal, the psychology of ongoing threat, and applied research employing stress and coping models. The disaster literature is particularly relevant to this climate change focus given the nature of the threats and impact events projected in the context of climate change. Yet there are a number of aspects of global climate change which make this phenomenon and aggregate of stressors distinct from other stressors and disasters and may alter the extent to which generalization is appropriate. These considerations include the global scope, magnitude, and temporal horizon of climate change, which may encompass many generations and likely many centuries, and the unprecedented character of such dramatic and consequential global changes in known human history.

Stressors are typically understood as events or circumstances that tax normal environmental transactions and relationships and initiate and motivate adaptation responses and stress and coping processes. In the climate change context stressors encompass direct, indirect, and mediated experiences with global climatic patterns and region-specific weather conditions and physical environmental impacts. Some communities, such as those located in regions of Alaska, Northern Canada, and Northern Europe are currently responding to direct contact with evident physical environmental impacts of climate change (e.g., Kolbert, 2006). 
Yet most communities in other regions of the world are responding to media images and coverage of climate change and social exchanges, with these images, texts, sound bites, documentaries, and conversations constituting powerful but indirect and virtual social representations of climate change and unfolding impacts. It is noteworthy that much of the media coverage of natural disasters around the world is being discussed, framed, and explained as manifestations of climate change. This suggests that the public in many parts of the world increasingly understand and see current and major natural disasters as dramatic, prophetic, and unfolding evidence of climate change. Current in-depth national survey research findings in Australia provide strong support for such public perceptions and understandings of the nexus between natural disasters and climate change (Reser et al., 2010) and along with more recent survey findings in North America (e.g., Yeager, Larson \& Krosnick, 2010; Leiserowitz, Smith \& Marlon, 2010) suggest that public belief in climate change, confidence in climate change science, and concern about climate change impacts remains very high, notwithstanding the media attention given to the views of skeptics and selective survey findings where issues with the framing of statements and questions and problematic response formats have led to distorting interpretations and reported findings. Those who directly experience the biophysical environmental impacts of climate change will likely experience stress due both to their immediate exposure to and personal experiences with climate change impacts as well as because of their shared and socially constructed anxieties, expectations, and understandings about future impacts of climate change. Types of stressors.

Discrete and continuous stressors. Climate change threat and impacts can be experienced as discrete events and as continuous environmental stressors (e.g., Aldwin \& Stokols, 1988; Wheaton, 1999). Discrete events represent sudden, extreme, environmental phenomena or life changing events, including natural disaster events such as hurricanes or 
tornados, that occur with little or no warning and impact a large number of people, and personal stressors (i.e., stressful life events), such as death and illness, that affect fewer people and may or may not be anticipated (e.g., Bell et al., 2001; Evans \& Cohen, 1991). Climate researchers have warned of more frequent and severe weather-related events including the increased frequency, heightened intensity, and extent of impact of natural disasters such as severe storms, hurricanes, tornadoes, floods, bush fires, and other rapid onset and largely unpredictable events.

In contrast, continuous stressful events or prolonged and adverse environmental conditions such as drought or a contaminated housing estate or mining region are viewed as chronic stressors and not event-specific. Ambient stressors are a type of chronic stressor particularly characteristic of environmental stressors (e.g., Bell et al., 2001). Ambient stressors can represent regional conditions of the environment, such as pollution or toxicity, that affect a large number of people but which may not be considered acute because they approximate low level background noise and may go unnoticed either because they are subtle or because people habituate to them (e.g., Adeola, 2000; Edelstein, 2002). Climate change can be understood as an ambient stressor encompassing periodic acute stressor events. Climate researchers have projected multiple and chronic stressor conditions, in the form of drought and other more incremental and persistent environmental changes, such as soil loss and erosion, salination, and desertification. Further, climate changes are often in the background due to these changes being embedded in natural variations in climate, the patterns being difficult to detect, the slow progression of the changes which can lead to a normalized habituation and expectancy, or the effects being perceived to be more relevant for future generations than one’s own..

Natural and technological disasters. In the disaster literature researchers point to both natural and technological disasters (resulting from technological processes and products) 
as differing types of cataclysmic events (e.g., Baum, Fleming, \& Davidson, 1983; Baum \& Fleming, 1993; VandenBos \& Bryant, 1987). Natural disasters are more sudden, cataclysmic, uncontrollable, acute (as distinct from chronic), and are characterised by enormous destructive power and magnitude. Technological disasters are attributed to human behavior (not the product of natural forces) and are less predictable, typically accompanied by no warning, are often chronic, often having no visible manifestation, are less familiar, more likely to threaten feelings of control, more likely to have complex impacts, less likely to elicit supportive and cohesive community response, and more likely to foster anger, frustration, resentment, felt helplessness, and blame.

Global climate change straddles this classification. Human 'forcing' of naturally occurring climate change is largely the product of technological processes and products, though consequent meteorological and climate change phenomena manifest as natural disasters. Indeed, climate change elicits some of the same responses found in the case of technological disasters, including distrust of government, corporations, regulatory authorities, and indeed science itself (e.g., Earle, 2004). Global climate change is also unique in that it presents multifaceted global impacts that will be chronic over a dramatic time frame, and constitutes a phenomenon not amenable to conventional national or jurisdictional agencies, or ‘disaster’ policies and procedures (e.g., Marshall et al., 2007). Many authors have suggested that framing global climate change in global disaster terms provides a clearer and more realistic picture of interacting processes and impacts, their true magnitude and extent, the nature and scale of human impacts, and the imperative to take immediate disaster mitigation and preparedness measures (e.g., Spratt \& Sutton, 2008; Reser \& Morrissey, 2008).

\section{Mediating transactions between stressors and coping responses}

Threat appraisals. Adaptation and stress and coping models highlight the roles that cognitive and affective processes play in risk appraisal and selection of coping responses. 
The more cognitive processes identified in these stress models focus on appraising or evaluating the stressor and possible adverse impacts on oneself and those important to oneself (e.g., friends, family members, colleagues). These appraisals include assessing the perceived risk of events, the severity of current or future damage, and who is vulnerable to the risks (e.g., Weber \& Stern, 2010). It is important to note that appraisals include assessing perceived psychological and human costs as well as the physical consequences of events. Climate changes can also be appraised as threatening because of their broader environmental impacts on all life on the planet and can be the cause of anticipatory grief and felt loss.

Risk perception and appraisal are influenced by social factors. Much information about the world and potential threats and problems comes mediated by way of our social world (e.g., Berger \& Luckmann, 1967; Gergen, 2009), through interactions with friends, overheard conversations, observations of others, media coverage, and specific risk communications from health professionals and climate change scientists-with these risk messages also being communicated through and edited by journalists and media organizations (e.g., Carvalho, 2007; Danesi, 2002), and via information and communication technologies including the internet (e.g., Olson \& Rejeski, 2005; Pettenger, 2007). Such vicarious experience, information exchange, and social learning includes the individual and cultural learning of adaptive practices and competencies with respect to risk, danger, and uncertainty (e.g., Bandura, 1999; Douglas \& Wildavsky, 1982; Kahan et al., 2007).

Social construction, social representation, and social amplification processes are three theoretical frameworks describing the complex factors which mediate and substantially influence the public’s appraisals of risk, environmental threat, and global environmental change (e.g., Bauer \& Gaskell, 2002; Pidgeon et al., 2003). These perspectives help explain variation in understandings of and responses to climate change across cultures, regions, and communities, and across environmental experts, journalists, scientists, and laypeople. 
Social construction as a process refers to how people collectively and through social interaction impose meaning and order on their world, how they perceive and interpret, construct and shape, their shared reality (e.g., Burr, 2003; Gergen, 2009). Social constructions are also understood as consensual understandings and operating constructs and classifications, thoughts and ideals, shared by members of a society which emerge through everyday conversation and transactions with each other and with the environment and world they share. Such entities as 'nature', 'the environment', 'environmental problems', 'natural' and 'technological' 'disasters', 'sustainability’ and “climate change” itself are viewed by many theorists and researchers as, in substantial part, social constructions (e.g., Macnaughten \& Urry, 1998; Pettenger, 2007). A considerable body of research helps us understand the nature and dynamics of such socially constructed and media-disseminated environmental threat representations and understandings (e.g., Adam, 1998; Johndon-Cartee, 2005; Weber, 2006). Hence this is an encompassing perspective of particular relevance to adaptation and coping, and public risk perceptions, understandings, and responses to 'climate change'.

Social representations are shared assumptions and understandings about the social and physical world (e.g., Moscovici, 2000). They include material culture expressions, images, texts, other information and communication technology products and information environments which capture and reflect particular world views. They provide a framework for the interpretation and communication of our experiences. It is through these commonly shared and collectively elaborated social representations that we make sense of the world and communicate that sense to each other (e.g., Deaux \& Philogene, 2001; Flick, 1998). Social representations of 'climate change' include media images, articles, books, magazine covers, documentary and popular culture films, research findings, and public discourse and shared understandings about 'climate change' and its nature, causes and environmental and human consequences. Many studies have been undertaken in North America and Europe which 
examine public risk perceptions of climate change, but few studies have undertaken in-depth investigations of the nature of media representations of climate change, or the underlying risk domain of climate change vis-à-vis other known environmental risks, or how or why climate change might be quite different from other risk domains in representation and with respect to public risk perceptions and appraisals and related psychological responses.

Social processes can both amplify and attenuate understandings of climate change (e.g., Pidgeon et al., 2003; Sjoberg, 2006). “The social amplification of risk framework holds that, as a key part of that communication process, risk, risk events, and the characteristics of both become portrayed through various risk signals (images, signs, symbols), which in turn interact with a wide range of psychological, social, institutional, or cultural processes in ways that intensify or attenuate perceptions of risk and its manageability” (Kasperson et al., 2003, p. 15). The research challenge has been to distil what these research findings and past policy applications of evidence-informed risk management principles have to say about how individuals and communities might best prepare themselves for what will be, for many, a very changed environmental and regulatory landscape in the context of climate change.

Coping appraisals. A second and more individually-oriented response domain related to cognitive processing of experienced and anticipated stressors focuses on the evaluation of responses one might make to the stressor. This includes assessing one's ability to engage in a behavior (i.e., self-efficacy), the perceived likelihood of a behavior to result in the desired outcome (i.e., response efficacy), perceived constraints on response options, and the relative perceived costs and benefits of respective responses. Costs and benefits are, of course, often unknown and therefore reflect a type of risk appraisal. Other coping appraisals involve assessing characteristics and resources of one's immediate social environment and community, such as the strength of one's social networks and neighborhood organization (e.g., Benight, 2004; Holahan \& Wandersman, 1991). Coping responses to various climate 
change impacts will be influenced by 'primary' appraisals of the specific impacts experienced or anticipated, and 'secondary' appraisals of the adaptation and mitigation responses could be made to these threats and/or impacts. Social processes and media portrayals are also very likely to influence primary and secondary threat appraisals and coping responses.

Interpretive and motivational responses and processes. How individuals respond to the perceived threat of climate change is likely influenced by the causal and responsibility attributions made in the context of climate change. Psychological research shows that people's willingness to restore or prevent damage is mediated by perceptions of the causes of the damage (e.g., Weiner, 1995). Such attributions, for instance, to either 'natural' or 'human' processes can influence appraisals of and the impact of events (Brun, 1992; Slovic et al., 2004). The distinction between natural and human-influenced causes may appear irrational in the face of consequential considerations, but plays a crucial role in considerations of perceived responsibility, accountability, and adaptation motivations. Even if people agree climate change is anthropogenically forced, they may not take personal responsibility for adjusting to current consequences or for preventing future impacts. Indeed research findings suggest that many may perceive global and distant others to be largely responsible for this global and distant ‘environmental problem’ instead of attributing personal or collective responsibility (e.g., Uzzell, 2000; 2004). Research is needed to specifically examine such interrelations in the context of global climate change and how these sense-making and human agency dynamics might relate to assessing and allocating blame and accountability for disasters.

The emotional side of risk perceptions, appraisals, and responses to climate change are likely to influence and mediate behavioral responses to climate change, and the importance of risk-as-feeling is not limited to individual level responses (Loewenstein et al., 2001; Slovic et al., 2004). Societal and cultural level emotional responses to media images 
and coverage of salient and menacing threats, such as radiation or seemingly cataclysmic future scenarios, both imbue and reflect strong affective and symbolic responses to threat, and are informed by culturally elaborated risk domains (e.g., Adam, 1998; Douglas \& Wildavsky, 1982). While only limited research has considered the nature and status of climate change as a risk domain vis a vis other risk domains (e.g., Townsend, Clarke, \& Travis, 2004), it is of particular importance to ask how emotional and symbolic aspects of climate change risk appraisals and sense making are influencing the nature and levels of public concern and underlying adaptation and protection motivation processes (e.g., Bohm, Nerb, McDaniels, \& Spada, 2001; Weinstein, 1989).

Perhaps the most frequently studied affective responses to stressful events relate to anxiety, fear, and worry, though other appraisal and self-efficacy related emotions are salient. Environmental stressors characteristically undermine people's perceived ability to predict and control the environments in which they live. A perceived lack of personal environmental control is one of the most ubiquitous determinants of aversiveness, anxiety, and distress (e.g., Evans \& Cohen, 1991; Shapiro, Schwartz \& Astin, 1995). Worry is an important psychological impact of climate change (see Doherty \& Clayton, 2010) which can also influence other parts of the adaptation process (e.g., Davey \& Wells, 2006). Fear, for instance in Protection Motivation Theory, is conceptualized as a response to and mediator of one's evaluation of the stressor (e.g., Rogers \& Prentice-Dunn, 1997). Fear and anxiety, while 'adaptive' responses to threat, can often 'get in the way' of clear thinking and very necessary adaptive responding in the context of imminent natural disaster warning situations (Reser, 2004). Other affective responses, such as hope, may act like optimism, by enhancing the likelihood that individuals will select coping strategies that engage one with the situation (Snyder, 2002). A taken for granted assumption within psychology that such intra-individual responses to the threat and perceived impacts of climate change are an important form of 
adaptation and a powerful mediator of overt adaptation behaviors is not widely appreciated or understood in the climate change science community. The nature and status of emotional responses to climate change is an important but currently unresolved conceptual and theoretical issue, as is the status of 'environmental concern(s)'.

Motivational processes are fundamental to considerations of psychological responses, impacts, and behavior change in the context of climate change. Most stress and coping models assume that the reduction of appraised threats motivates individuals to initiate coping responses. The Health Belief Model, for instance, is premised on the assumption that people are prepared to undertake preventive behavior(s) as a function of their appraisal of the severity of a threat, the perceived benefits of a recommended health action, and the perceived barriers to taking such action (e.g., Janz \& Becker, 1984). Cognitive adaptation approaches (e.g., Aspinwall, 2004; Lehman \& Taylor, 1987; Taylor, 1983; Taylor \& Shepperd, 1998; Taylor \& Stanton, 2007) are also central to understanding intra-individual psychological adaptation processes, and the suite of cognitive and emotional heuristic strategies employed to achieve a manageable world (e.g., Slovic, 2000). Motivated reasoning perspectives argue that functional, self-serving needs lead us to selectively seek information, evaluate evidence, and form conclusions that validate existing, unreflective, beliefs and enhance self perception and esteem (e.g., Kunda, 1990; Leary, 2006). Other motivational responses to environmental threat and stress have received substantial psychological attention: instinctive fight or flight responding, drives to survive as described in evolutionary psychology, psychoanalytic defense mechanisms, goal setting, and various manifestations of protection motivation, whether through attitudinal stance, value expression, avoidance, defensive pessimism or unrealistic optimism (e.g., Taylor \& Brown, 1988; Weinstein \& Kline, 1996). These and other motivational and sense-conferring considerations can substantially inform our understanding of adaptation and coping responses in the face of climate change. 
A central emphasis over the past several decades in the area of environmental psychology (e.g., Bell et al., 2001; Bonnes \& Bonaiuto, 2002; Gifford, 2007) has been that of environmental concern(s), and the role which this risk appraisal process and outcome, and accompanying motivational state, plays in adopting pro-environmental behaviors and possibly mediating psychological distress (e.g., Hansla, Gamble, Juliusson, \& Garling, 2008; Schmuck \& Schultz, 2002). This focus on concern has also been very typical of popular culture coverage and debate with respect to the human impacts of climate change (e.g., Carvalho, 2007; Kluger, 2006; Lowe et al., 2006). But current conceptualizations of environmental concern(s) as construct, risk response, and motivational state have not adequately addressed the nature, scope, and uncertainty of global climate change, nor its important spatial, temporal, and cultural referents and meanings.

These convergent literatures are routinely drawn upon by psychologists when addressing environmental risks and natural and technological hazard preparedness and response (e.g., Cvetkovich \& Earle, 1992; O’Riordan, 1995). Such psychological considerations and research findings are often not recognized or utilized in interdisciplinary considerations and discourses, with climate change being a particularly salient case in point. More recently a number of psychology research teams have begun to systematically compare and contrast public risk perceptions, appraisals and psychological response to global climate change as contrasted with nuclear energy facilities (e.g., Pidgeon, Lorenzoni \& Poortinga, 2008; Spence, Pidgeon \& Uzzell, 2008). This research draws on an extensive research base compiled since 1979 in the wake of Three Mile Island (TMI) and other nuclear power station accidents (e.g., Baum \& Fleming, 1993; Baum, Fleming \& Davidson, 1983) and has since been directed to many technological and natural environmental threats (e.g., Edelstein, 2002). The research with nuclear facilities and accidents, such as that at TMI has conclusively shown that information itself about technological risks can be threatening and anxiety- 
inducing, leading to very real mental and physical health impacts. In this context, for example, emotionally-focused coping strategies were associated with less stress than problem-focused coping and denial. In many large scale disaster contexts, being able to anticipate and manage one's risk perceptions and psychological response in the context of largely uncontrollable external events and consequences confers very real and psychologically adaptive benefits (e.g., Taylor, 1983; Aspinwall, 2010; Aspinwall \& Taylor, 1997; Reser \& Morrissey, 2008).

\section{Types of adaptation and coping responses}

Coping responses include actions or inhibitions of single, multiple, and repeated behaviors engaged in by individuals or groups as well as intra-individual responses to climate change. These responses can be proactive (also known as anticipatory adaptation and psychological preparedness), made in anticipation of an event, or reactive, made after an event (e.g., Aspinwall, 2010; Aspinwall \& Taylor, 1997). The two merge when responses are made to an event in order to diminish the impact of a current event while simultaneously addressing future events. For instance, individuals who rebuild their homes after a natural disaster may be adapting to changes that have occurred while at the same time enhancing protection from future disasters. Nonetheless, the differentiation is useful when thinking about coping with climate change because many people may not be responding to currently occurring events attributable to climate change but are instead responding to anticipated events. Thus, addressing successful coping in the context of global climate change requires a thoughtful consideration of prevention and preparedness (e.g., Ball, 2008; Keim, 2008).

Different literatures emphasize different types of coping responses. The stress and coping literature has emphasized individual coping responses. Intra-individual responses to experienced or anticipated experiences include responses such as denial, environmental numbness, cognitive reappraisals, and emotion regulation (e.g., Carver \& Sheier, 1998). 
Other individual responses are overtly behavioral such as seeking information, seeking social support, or engaging in problem solving by changing one’s habitat to adjust to climate changes, or engaging in mitigation. In contrast, research on environmental stressors and natural disasters has been more likely to include community level responses (e.g., Gow \& Paton, 2008; Peek \& Mileti, 2002). Community responses to stressors include volunteerism and helping neighbors cope with lack of water, basic amenities, or destruction of one’s home. It is not uncommon for groups to emerge after disasters that help communities cope with crises, reflecting the interactive dynamics of collective coping, community resilience, and a crisis-initiated and renewed group identity and sense of community (e.g., Holahan \& Wandersman, 1991; Gow \& Paton, 2008). These community responses may be particularly important to take into account when considering coping with the impacts of climate change given the breadth and duration of the impacts, and the differential impacts of climate change for communities in differing geographic and socioeconomic circumstances. In the context of climate change, additional and specific types of psychological and social responses that have not typically been examined in past research may need to be addressed, such as abandoning social or moral order, reliance on dogmatic beliefs, or rejecting consumer driven lifestyles (e.g., Eckersley, 2008).

\section{Moderators of adaptation and coping processes}

Many personal and contextual variables have been theorized and tested as predictors and moderators of individuals' and communities' adaptation and coping responses and many of these are likely to be important factors in public adaptation to climate change (e.g., Bell et al., 2001; Winkel et al., 2009). Several examples are listed in Figure 1. Sometimes these variables predict appraisals and preferences for coping responses, such as when optimism predicts the tendency to use problem-focused coping in reaction to a stressor (e.g., Scheier, Weintraub, \& Carver, 1986). At other times the constructs will moderate relations between 
the variables in the model such as when the constructs predict the impact of these appraisals on the coping response (i.e., moderators of the impact of appraisals on coping responses) and when the construct predicts the consequences of coping responses (i.e., moderate the relations between coping responses and outcomes; the latter are discussed in Doherty \& Clayton, 2010). For instance, neuroticism has been shown to influence not only the choice of coping responses but also the impact of coping responses on wellbeing (Bolger \& Zuckerman, 1995).

Two constructs often discussed in the climate change literature are resilience and vulnerability. In this literature resilience typically refers to the adaptive capacity of "resilient social-ecological systems” (e.g., Schipper \& Burton, 2009). Within psychology, and in the case of individuals, the construct of 'resilience' typically refers to inner strengths and coping resources for necessary adaptation to situational demands. In the case of communities, it refers to social strengths and capacities of a community such as in the form of pooled resources, knowledge, social supports, and social capital (e.g., Bonanno, 2004; Luthar, 2003; Masten, 2001; Schoon, 2006). 'Resilience' has become the principal theme in the APA's web-based help line and brochures providing advice and guidance in the context of disasters and terrorism (e.g., American Psychological Association, 2007; Newman, 2005).

Vulnerability refers to the extent to which systems and individuals are susceptible to, and unable to cope with, adverse effects of climate change. Vulnerability is a function of the characteristics of climate change impacts (e.g., their magnitude and rate of change) and variation in systems and individuals (e.g., degree of exposure to climate change impacts, individual and community adaptive capacity, and connectedness to communities). It has also been well documented, most recently and dramatically in the aftermath of Hurricane Katrina, that vulnerabilities can be endemic to systems and places as well as integral to life circumstances, prior experiences, and socioeconomic and racial disadvantage (e.g., Cutter, Boruff \& Shirley, 2003; Cutter et al., 2006). Vulnerability in psychological contexts is also a 
very important experiential and risk appraisal domain and psychological response, which is often not commensurate with objective risk assessment and which typically reflects cultural and often symbolic meanings and associations as well as individual difference considerations.

\section{Discussion}

The question addressing adaptation in the context of climate change framed by the APA Taskforce was 'How do people adapt to and cope with the perceived threat and unfolding impacts of climate change?' This brought necessary specification to that which people are adapting to, and to the construct and processes of adaptation, and facilitated a clearer and strategic consideration of convergent theoretical and research areas which seemed of particular value in identifying and profiling relevant psychological work. The matter of what people are adapting to is in our view critical, albeit complex, as 'climate change' is clearly far more than the objective environmental consequences and impacts of altered atmospheric climate patterns. It is also one thing to review how individuals and communities have coped with a devastating set of environmental changes such as a decades-long drought, or a catastrophic event such as 9/11 or Hurricane Katrina, or that body of literature relating to more personal life changes and crises, but quite another to address how individuals and communities will adapt and cope with an encompassing spectrum of global environmental changes profound in scope and consequences and possibly extending into the next millennium. Yet adaptation to climate change also constitutes a quintessentially psychological matter and our discipline has considerable experience and depth in related risk, disaster, crises, and promotion of health and wellbeing contexts, and the matter at issue is human response to dramatically changing behavior contexts, settings, and natural environments.

While we focused on adaptation in this article, it is difficult to separate psychosocial and mental health impacts from adaptation processes and responses, either analytically or 
operationally. They are intertwined aspects of psychological response to the complex phenomenon of global climate change. Public perceptions, appraisals, understandings, motivations, and consequent psychological and behavioral responses to climate change representations and physical environmental consequences are all integral and inter-related features of psychological adaptation to the ongoing and unfolding psychosocial impacts of global climate change. Having said this, it is important to closely consider, and to bring theoretical and analytic clarity to, the construct and processes of adaptation in the context of climate change, both to communicate the too-often neglected mediating roles and dynamics of psychological processes when discussing 'adaptation' in the context of climate change, and to profile the crucial value of an encompassing ecological and multi-level psychological perspective when considering climate change impacts, interventions, and policy considerations (e.g., Winkel et al., 2009).

A challenge in addressing adaptation in the context of climate change is that adaptation is such a fundamental part of psychology's assumptive and theoretical world when addressing human behavior and in particular people-environment transactions that it is not always easy or useful to differentiate adaptation from closely related and/or interacting processes such risk perception and appraisal, sense making, coping, psychological impacts, and multiple types of intra-individual and extra-individual responses and adjustments. These processes all fall within the compass of adaptation and the reciprocal adjustments which characterize characterize people-environment transactions. Indeed from a psychological vantage point it is arguable that climate change adaptation and mitigation are closely interlinked, in that it is one's psychological response to the climate change threat and one's changed thinking, feelings, motivations and concerns that powerfully mediate the extent to which one engages in environmentally significant behavior (i.e., behavior which reduces one’s carbon footprint, e.g., Stern, 2010). What has received insufficient attention is that it is 
often the psychological significance of one's behavior and response to perceived environmental issues that is personally meaningful and motivating. The prevailing distinction between adaptation and mitigation made in the climate change science literature is understandable and arguably useful, but problematic in terms of the motivations, meaningfulness, and consequences of one's actions and their relationship to psychological adaptation. Indeed more recent interdisciplinary discussions are acknowledging that adaptation and mitigation are in fact closely interlinked, with this realization itself suggesting an important research front (e.g., Brewer, 2008).

The challenges of addressing the threat and environmental impacts of global climate change highlight multiple areas of research need and cross-domain collaboration possibilities, both within psychology and across the social and natural sciences. A more 'environmental' psychological perspective places particular emphasis on important changes taking place in the human landscape in response to environmental changes and impacting processes. In the context of human response and adaptation to climate change, there exist a number of areas of crucial need and strategic importance.

- There is a clear need to be able to more adequately and sensitively measure, document, and monitor significant changes over time taking place in the human landscape with credible and meaningful psychological and social indicators which relate to psychological and social responses to and the psychosocial impacts of the threat and environmental consequences of climate change. (e.g., Li, 2010; Stokols et al., 2009).

- A pressing research challenge is to more closely address the matter of local versus global environments and places; how these space/place perceptions and connections relate to environmental concerns, engagements, responsibility attributions, and perceived efficacy; and how very consequential psychological adaptations to climate 
change might well involve making the global more local, and the local more global, through meaningful personal engagement at a local level with this global threat and challenge (e.g., Uzzell, 2004; Whitmarsh, O’Neill \& Lorenzoni, 2010).

- An important and related research domain relates to the relative importance of direct exposure to and experience with environmental changes and impacts associated with climate change as distinct from indirect or vicarious experience through media coverage, environmental documentaries, on line inquiries, and interpersonal exchange. Given the pervasiveness of media coverage of climate change, it is important to further explore and document emotional and other reality-conferring message features which can make virtual exposure to and experience with the realities of climate change more direct, personal, and motivating (e.g., Moser \& Dilling, 2004; Ornstein \& Ehrlich, 1990 ).

- There exist very few studies of the risk domain status and cultural meaning contexts and parameters of 'climate change'. This neglected research domain relates closely to that of the social representations of global climate change, and how media images and popular science depictions are influencing public understandings of, perceived risk, other psychological responses to the phenomenon of climate change (e.g., O’Neill \& Hulme, 2009). Using what is known about adaptation and coping could be used to develop interventions to aid psychological and physical adaptation, as has been done in health psychology (e.g., Aspinwall, 2010; Taylor, 2006), and to develop policy recommendations.

- Psychological perspectives on climate change adaptation highlight a number of crucial but currently neglected aspects of adaptation in multi- and interdisciplinary perspectives on adaptation. These include multi-leveled approaches and analytic frameworks that encompass individual and experience-focused levels of analysis, 
social psychological and motivational process responses to the threat and unfolding impacts of climate change, and environmental psychological models, constructs, and indicators relevant to assessing the psychosocial contexts and impacts of climate change (e.g., Gifford, Steg \& Reser, 2011; Wapner et al, 2000).

Psychological research on human response to global environmental change conservatively spans three decades (e.g., Chen, Boulding \& Schneider, 1983; National Research Council, 1992, 2009; Stern \& Gardner, 1981), providing particularly helpful perspectives and insights on human adaptation and adjustment to environmental threat, natural and technological disasters, and stressful and challenging environmental changes. But this highly relevant and extensive body of theoretical approaches, research findings, and evidence-based applications continues to be a relatively unfamiliar disciplinary landscape in the environmental sciences. Of particular importance is the conceptual framing and theoretical elaboration of intra-individual and social psychological adaptation processes which would appear to be powerfully mediating public risk perceptions and understandings, effective coping responses and resilience, overt behavioral adjustment and change, and psychological and social impacts in the context of climate change. This psychological window on climate change adaptation is arguably indispensable to genuinely multidisciplinary and interdisciplinary research and policy initiatives addressing the impacts of climate change (Stokols et al., 2008). 


\section{References}

Adam, B. (1998). Timescapes of modernity: The environment and invisible hazards. London: Routledge.

Adeola, F. (2000). Endangered community, enduring people: Toxic contamination, health, and adaptive responses in a local context. Environment and Behavior, 32, 209-249.

Aldwin, C. \& Stokols, D. (1988) The effects of environmental change on individuals and groups: Some neglected issues in stress research. Journal of Environmental Psychology, 8, 57-75.

American Psychological Association. (2007). The Road to Resilience. Retrieved June 15, 2009, from http://www.APAHelpCenter.org/resilience

Aspinwall, L.G. (2010) Future-oriented thinking, proactive coping, and the management of potential threats to health and well-being. In S. Folkman (Ed) The Oxford handbook of stress, health and coping. New York: Oxford University Press.

Aspinwall, L. G. (2004). Dealing with adversity: Self-regulation, coping, adaptation, and health. In A. Tesser \& N. Schwarz (Eds.), Blackwell handbook of social psychology: Intraindividual processes (pp. 591-614). Oxford: Blackwell Publishing.

Aspinwall, L. G., \& Taylor, S. E. (1997). A stitch in time: Self-regulation and proactive coping. Psychological Bulletin, 121(3), 417-436.

Ball, M. (2008). Prevention - psychology’s forgotten mission. The Psychologist, 21, 602-603.

Bandura, A. (1999). Social learning. In A. S. R. Manstead, M. Hewstone, S. T. Fiske, M. A. Hogg, H. T. Reis \& G. R. Semin (Eds.), The Blackwell encyclopedia of social psychology (pp 576-581). Oxford, UK: Blackwell Publishing.

Bauer, M. W. \& Gaskell, G. (Eds). (2002). Biotechnology: The making of a global controversy. Cambridge, UK: Cambridge University Press. 
Baum, A., Fleming, R., \& Davidson, L. M. (1983). Natural disaster and technological catastrophe. Environment and Behavior, 15, 333-354.

Baum, A., \& Fleming, I. (1993). Implications of psychological research on stress and technological accidents. American Psychologist, 48, 665-672.

Bell, P. A., Greene, T. C., Fisher, J. D., \& Baum, A. (2001). Environmental psychology (5 ${ }^{\text {th }}$ ed.). Fort Worth: Harcourt College Publishers.

Benight, C.C. (2004) Collective efficacy following a series of natural disasters. Anxiety, Stress and Coping, 17, 401-420.

Berger, P. L. \& Luckmann, T. (1967). The social construction of reality. Hammondsworth: Penguin.

Bohm, G., Nerb, J., McDaniels, T., \& Spada. (Eds). (2001). Environmental risks: Perception, evaluation, and management [Special Issue]. Research in Social Problems and Public Policy, 9, xi-xx.

Bolger, N., \& Zuckerman, A. (1995). A framework for studying personality in the stress process. Journal of Personality and Social Psychology, 69, 890-902.

Bonanno, G. A. (2004). Loss, trauma, and human resilience: Have we underestimated the human capacity to thrive after extremely aversive events? American Psychologist, 59, 20-28.

Bonnes, M., \& Bonaiuto, M. (2002). Environmental psychology: From spatial-physical environment to sustainable development. In R.B. Bechtel \& A. Churchman (Eds.), Handbook of environmental psychology (pp. 28-54). New York: Wiley.

Brewer, J.F. (2008) New directions in climate change vulnerability, impacts, and adaptation assessment: Summary of a workshop. Washington, D.C.: National Academies Press. Brun, W. (1992). Cognitive components in risk perception: Natural versus manmade risks. Journal of Behavioral Decision Making, 5, 117-132. 
Burr, V. (2003). An introduction to social constructionism. Second edition. London, UK: Routledge.

Carvalho, A. (2007). Ideological cultures and media discourses on scientific knowledge: Rereading news on climate change. Public Understanding of Science, 16, 223-243.

Carver, C. S., \& Scheier, M. F. (1998). On the self-regulation of behavior. New York: Cambridge University Press.

Chen, R.S., Boulding, E. \& Schneider, S.H. (1983) (Eds) Social science research and climate change. Dordrecht: D. Reidel Publishing Company.

Cutter, S.L., Emrich, C.T., Mitchell, J.T., Boruff, B.J., Gall, M., Schmidtlein, M.C. Burton, C.G. \& Melton, G. (2006) The long road home: Race, class and recovery from Hurricane Katrina. Environment, 48(2) 8-20.

Cutter, S.L, Boruff, B.J. \& Shirley, W.L. (2003) Social vulnerability to environmental hazards. Social Science Quarterly, 84 (2) 242-261.

Cvetkovich, G. \& Earle, T. C. (Eds.). (1992). Public responses to environmental hazards. Journal of Social Issues, 48(4). [Entire Issue].

Danesi, M. (2002). Understanding media semiotics. London: Arnold.

Davey, G.C.L. \& Wells, A. 2006) Worry and its psychological disorders: Theory, assessment and treatment. Chichester: Wiley.

Deaux, K, \& Philogene, G. (Eds). (2001). Representations of the social. Oxford, UK: Blackwell Publishers.

Douglas, M., \& Wildavsky, A. (1982). Risk and Culture: An essay on the selection of technological and environmental dangers. Berkeley: University of California Press.

Earle. T. C. (2004). Thinking aloud about trust: A protocol analysis of trust in risk management. Risk Analysis, 24, 169-183. 
Eckersley, R. (2008). Nihilism, fundamentalism, or activism: Three responses to fears of the apocalypse. The Futurist, January-February, 35-39.

Edelstein, M. R. (2002). Contamination: The invisible built environment. In R. B.Bechtel \& A. Churchman (Eds.), Handbook of environmental psychology (pp. 559-588). New York: Wiley.

Evans, G. W. \& Cohen, S. (1991). Environmental Stress. In D. Stokols \& I. Altman (Eds.), Handbook of Environmental Stress. (Vol. 1: pp. 571-610). Malabar, FL: Krieger.

Evans, G. W. \& Stecker, R. (2004). Motivational consequences of environmental stress. Journal of Environmental Psychology, 24, 143-165.

Flick, U. (1998). Everyday knowledge in social psychology. In U. Flick (Ed.), The psychology of the social (pp. 41-59). Cambridge, UK: Cambridge University Press.

Gergen, K.J. (2009) An invitation to social construction. Second edition. London: Sage.

Gifford, R. (2007). Environmental psychology: Principles and practice. Colville, WA: Optimal Books.

Gifford, R., Steg, L. \& Reser, J.P. (2011) Environmental psychology. In P.R. Martin, F.M. Cheung, M.C. Knowles, M’ Kyrios, L. Littlefied, J.B. Overmeier \& J.M. Prieto (Eds) The IAAP handbook of applied psychology (pp 440-470). London: Blackwell Publishing.

Gifford, R., Scannell, L., Kormos, C., Smolova, L., Biel, A., Boncu, S., et al. (2009). Temporal pessimism and spatial optimism in environmental assessments: An 18nation study. Journal of Environmental Psychology, 29, 1-12.

Glanz, K., Rimer, B. K., \& Lewis, F. M. (2002). Health behavior and health education: Theory, research and practice. San Francisco: Wiley \& Sons.

Gow, K., \& Paton, D. (Eds.). (2008). The phoenix of natural disasters: Community resilience. New York: Nova Science Publishers. 
Grauman, C.F. \& Kruse, L. (1990) The environment: Social construction and psychological problems. In H.T. Himmelweit \& G. Gaskell (Eds) Societal psychology (pp 212-229). London: Sage.

Hansla, A., Gamble, A., Juliusson, A., \& Garling, T. (2008). The relationships between awareness of consequences, environmental concern, and value orientations. Journal of Environmental Psychology, 28, 1-9.

Holahan, C. J. (1982). Environmental Psychology. New York: Random House.

Holahan, C. J. \& Wandersman, A. (1991). The community psychology perspective in environmental psychology. In D. Stokols \& I. Altman (Eds.), Handbook of environmental stress (Vol 1, pp. 827-861). Malabar, FL: Krieger.

Hulme, M. (2009) Why we disagree about climate change?: Understanding controversy, inaction and opportunity. Cambridge, UK: Cambridge University Press.

Intergovernmental Panel on Climate Change [IPCC]. (2007a). Climate Change 2007: Synthesis Report. Pachauri, R.K. \& Reisinger, A. (Eds.). IPCC: Geneva, Switzerland. Intergovernmental Panel on Climate Change [IPCC]. (2007b). Glossary of Terms used in the IPCC Fourth Assessment Report: Working Group II (WG2). Retrieved June 15, 2009, from http://www.ipcc.ch/glossary/

Janz, N. K., \& Becker, M. H. (1984). The health belief model: A decade later. Health Education Quarterly, 11(1), 1-47.

Johndon-Cartee, K. S. (2005). News narratives and news framing: Constructing political reality. Lanhan, MD: Rowan \& Littlefield.

Kahan, D.M., Braman, D., Slovic, P., Gastil, J. \& Cohen, G. (2007) The second national risk and culture study: Making sense of - and making progress in - the American culture war of fact. Report of the Cultural Cognition Project at Yale Law School. New Haven CN: Yale Law School. 
Leiserowitz, A., Smith, N. \& Marlon, J.R. (2010) America's knowledge of climate change.

New Haven, CT: Yale University, Yale Project on Climate Change Communication. Kasperson, J.X., Kasperson, R.E., Pidgeon, N. \& Slovic, P. (2003) In N. Pidgeon, R.E. Kasperson \& P. Slovic (Eds) The social amplification of risk (pp13-46). Cambridge, UK: Cambridge University Press.

Keim, M. E. (2008). Building human resilience: The role of public health preparedness and response as an adaptation to climate change. American Journal of Preventive Medicine, 35, 508-516.

Kluger, J. (2006b, April 3). Global warming. Time, 28-42.

Kolbert, E. (2006). Field notes from a catastrophe: Man, nature and climate change. New York: Bloombury.

Kunda, Z. (1990) The case for motivated reasoning. Psychological Bulletin, 108 (3) 480-498.

Leary, M.R. Motivational and emotional aspects of the self. Annual Review of Psychology, 58, 317-344.

Lazarus, R.S. (1991) Emotion and adaptation. New York: Oxford University Press.

Lazarus, R. S., \& Cohen, J. B. (1977). Environmental stress. In I. Altman \& J. F. Wohlwill (Eds), Human behavior and environment: Advances in theory and research (pp. 90127). New York: Plenum.

Lazarus, R. S., \& Folkman, S. (1984). (Eds.). Stress, appraisal and coping. New York: Springer.

Leary, N., Adejuwon, J., Barros, V., Burton, I., Kulkarni, J. \& Lasco, R. (2008) (Eds) Climate change and adaptation. London: Earthscan.

Lehman, D., \& Taylor, S. E. (1987). Date with an earthquake: Coping with a probable, unpredictable disaster. Personality and Social Psychology Bulletin, 13, 546-555. 
Lepore, S. J. \& Evans, G. W. (1996). Coping with multiple stressors in the environment. In M. Zeidner, \& N.S. Endler (Eds.), Handbook of coping: Theory, research and applications (pp. 350-377). New York: Wiley.

Li, R.M. (2010) The importance of common metrics for advancing social science theory and research: A workshop summary. Washington, DC: The National Academies Press.

Loewenstein, G. F., Weber, E. U., Hsee, C. K., \& Welch, E. (2001). Risk as feelings. Psychological Bulletin, 127, 267-286.

Lowe, T., Brown, K., Dessai, S., DeFrancea, D. M., Haynes, K. \& Vincent, K. (2006). Does tomorrow ever come? Disaster narrative and public perception of climate change. Public Understanding of Science, 15, 435-457.

Luthar, S. A. (2003). Resilience and vulnerability: Adaptation in the context of childhood adversities. New York: Cambridge University Press.

Macnaghten, P., \& Urry, J. (1998). Contested natures. London: Sage.

Marshall, R. D., Bryant, R. A., Amsel, L. Suh, E. J., Cook, J. M. \& Neria, Y. (2007). The psychology of ongoing threat: Relative risk appraisal, the September 11 attacks, and terrorism-related fears. American Psychologist, 62, 304-316.

Martin, I. (1964) Adaptation. Psychological Bulletin, 61, 35-44.

Masten, A. S. (2001). Ordinary magic: Resilience processes in development. American Psychologist, 56(3), 227-238.

Moscovici, S. (2000). Social representations: Explorations in social psychology. Cambridge: Polity Press.

Moser, S.C. \& Dilling, L. (2004) Making climate change hot: Communicating the urgency and challenge of climate change. Environment, 46 (10) 32-46.

Morrissey, S. A., \& Reser, J. P. (2007). Natural disasters, climate change and mental health considerations in rural Australia. Australian Journal of Rural Health, 15, 120-125. 
National Research Council. (1992). Global environmental change: Understanding the human dimensions. Stern, P. C., Young, O. R., \& Druckman, D. (Eds.). Washington, DC: National Academies Press.

National Research Council. (2009). Understanding and responding to climate change. Washington, DC: National Research Council/The National Academies.

Newman, R. (2005). APA’s resilience initiative. Professional Psychology: Research and Practice, 36, 227-229.

Norris, F.H., Stevens, S.P., Pfefferbaum, B., Wyche, K.F. \& Pfefferbaum, R.L. (2008) Community resilience as a metaphor, theory, set of capacities, and strategy for disaster readiness. American Journal of Community Psychology, 41, 127-150.

Olson, R., \& Rejeski, D. (2005). Environmentalism and the technologies of tomorrow: Shaping the next industrial revolution. Washington, DC: Island Press.

O’Neill, S.J. \& Hulme, M. (2009) An iconic approach for representing climate change. Global Climate Change, 19, 402-410.

O’Riordan, T. (Ed.). (1995). Perceiving environmental risks. New York: Academic Press. Ornstein, R. \& Ehrlich, P. (1990) New world: New mind. New York: Simon \& Schuster. Pachauri, R.K. (2008) Foreword. In N Leary, J. Adejuwon, V. Barros, I. Burton, J. Kulkarni, \& R. Lasco (Eds) Climate change and adaptation (xiv). London: Earthscan.

Peek, L. A. \& Miletti, D. S. (2002). The history \& future of disaster research. In R. B. Bechtel, R. B., \& A. Churchman (Eds.), Handbook of environmental psychology (pp. 511-524). New York: Wiley.

Pettenger, M.E. (2007). The social construction of climate change. London: Ashgate. Pidgeon, N. F., Kasperson, R. K. \& Slovic, P. (2003). The social amplification of risk. Cambridge: Cambridge University Press. 
Pidgeon, N., Lorenzoni, I., \& Poortinga, W. (2008). Climate change or nuclear power - No thanks! A quantitative study of public perceptions and risk framing in Britain. Global Environmental Change, 18, 69-85.

Pielke, R., Prins, G.P., Rayner, S. \& Sarewitz, D. (2007) Lifting the taboo on adaptation. Nature, 445, 597-598.

Reser, J. P. (2004). The experience of natural disasters: Psychological perspectives and understandings. In J. P. Stoltman, J. Lidstone \& L. M. DeChano (Eds.), International perspectives on natural disasters: Occurrence, mitigation, and consequences (pp. 369-384). Dordrecht: Kluwer Academic.

Reser, J. P. (2010). A psychological perspective on ‘thinking globally and acting locally’ in the context of climate change. Keynote address to the International Congress of Applied Psychology July 11-16, Melbourne.

Reser, J.P., Pidgeon, N., Spence, A., Bradley, G.; Glendon, I. \& Ellul, M. (2010) Public perceptions of climate change in Australia and Great Britain. Gold Coast, Qld: Griffith University, Griffith Climate Response Program.

Reser, J. P. \& Morrissey, S. A. (2008). Situating and framing individual and community experience and response: A psychological perspective. In K. Gow \& D. Paton (Eds.), The phoenix of natural disasters: Community resilience (pp. 47-72). New York: Nova Science Publishers.

Reyes, G. \& Jacobs, G.A. (Eds.). (2006). Handbook of international disaster psychology (Vol.1-4). Westport, CT: Praeger.

Rogers, R. W., \& Prentice-Dunn, S. (1997). Protection motivation theory. In D. S. Gochman (Ed.), Handbook of health behavior research 1: Personal and social determinants (pp. 113-132). New York: Plenum Press. 
Scheier, M. F., Weintraub, J. K., \& Carver, C. S. (1986). Coping with stress: Divergent strategies of optimists and pessimists. Journal of Personality and Social Psychology, 51(6), 1257-1264.

Schipper, E.L.F. \& Burton, I. (2009) (Eds) The Earthscan reader on adaptation to climate change. London: Earthscan.

Schoon, I. (2006). Risk and resilience: Adaptations in changing times. Cambridge: Cambridge University Press.

Schmuck, P., \& Schultz, W. P. (Eds.). (2002). Psychology of sustainable development. Boston, MA: Kluwer Academic Publishers.

Shapiro, D. H., Schwartz, C. E., \& Astin, I. A. (1996). Controlling ourselves, controlling our world. American Psychologist, 51, 1213-1230.

Sjoberg, L. (2006). As time goes by: The beginnings of social and behavioral science risk research. Journal of Risk Research, 9(6) 601-604.

Slovic, P. (2000). The perception of risk. London: Earthscan.

Slovic, P., Finucane, M. L., Peters, E., et al. (2004). Risk as analysis and risk as feelings: Some thoughts about affect, reason, risk and rationality. Risk Analysis, 24, 311-322

Smith, N.W. \& Joffe, H. (2009) Climate change in the British press: The role of the visual. Journal of Risk Research, 12, 647-663.

Snyder, C. R. (2002). Hope theory: Rainbows in the mind. Psychological Inquiry, 13, 249275.

Spence, A., Pidgeon, N., \& Uzzell, D. (2008). Climate change - psychology’s contribution. The Psychologist, 21, 108-11.

Spratt, D., \& Sutton, P. (2008). Climate code red: The case for a sustainable emergency. Fitzroy, Melbourne: Friends of the Earth. 
Stern, P.C. \& Gardner, G. (1981) Psychological research and energy policy. American Psychologist, 36, 329-342.

Stokols, D. (1978). Environmental psychology. Annual Review of Psychology, 29, 253-295.

Stokols, D., Misra, S., Hall, K., Taylor, B. \& Moser, R. (2008) The ecology of team science: Understanding contextual influences on transdisciplinary collaboration. American Journal of Preventive Medicine, 35, (2, Suppl. 1) S96-S115.

Stokols, D., Misra, S., Runnerstrom, M. G. \& Hipp, A. (2009). Psychology in an age of ecological crisis. American Psychologist, 64, 181-193.

Taylor, K. M., \& Shepperd, J. A. (1998). Bracing for the worst: Severity, testing, and feedback timing as moderators of the optimistic bias. Personality and Social Psychology Bulletin, 24, 915-926.

Taylor, S. E. (1983). Adjustment to threatening events: A theory of cognitive adaptation. American Psychologist, 38, 1161-1173.

Taylor, S. E. (2006). Health psychology (6 ${ }^{\text {th }}$ ed.). New York: McGraw-Hill.

Taylor, S. E., \& Brown, J. D. (1988). Illusion and well-being: A social psychological perspective on mental health. Psychological Bulletin, 103(2), 193-210.

Taylor, S. E. \& Stanton, A. L. (2007). Coping resources, coping processes, and mental health. Annual Review of Clinical Psychology, 3, 377-401.

Townsend, E., Clarke, D. D. \& Travis, B. (2004). Effects of context and feelings on perceptions of genetically modified food. Risk Analysis, 24, 1369-1384.

Uzzell, D. L. (2000). The psycho-spatial dimensions of global environmental problems. Journal of Environmental Psychology, 20(4), 307-318.

Uzzell, D. (2004). From local to global: A case of environmental hyperopia. IHDP Update, 4, 6-7. 
Vaughan, E. (1993). Individual and cultural differences in adaptation to environmental risks. American Psychologist, 48, 673-680.

VandenBos, G.R. \& Bryant, B.K. (1987) (Eds.), Cataclysms, crises, and catastrophes.

Washington, DC: American Psychological Association.

Wagner, W. \& Hayes, N. (2005) Everyday discourse and common sense: The theory of social representations. New York: Palgrave Macmillan.

Wapner, S., Demick, J., Yamamoto, T. \& Minami, H. (2000) (Eds) Theoretical perspectives in environment-behavior research: Underlying assumptions, research problems, and methodologies. New York: Kluwer Academic/Plenum Publishers.

Weber, E. U. (2006). Evidence-based and description-based perceptions of long-term risk: Why global warming does not scare us (yet). Climatic Change, 77, 103-120.

Weiner, B. (1995) Judgments of responsibility: A foundation for a theory of social conduct. New York: Guilford Press.

Weinstein, N. D. \& Kline, W. (1996). Unrealistic optimism: Present and future. Journal of Social and Clinical Psychology, 15, 1-8.

Weinstein, N. H. (Ed.). (1988). Taking care: Understanding and encouraging self-protective behavior. Cambridge: Cambridge University Press.

Wheaton, B. (1999). The nature of stressors. In A. V. Horwitz, \& T. L. Scheid (Eds.), A handbook for the study of mental health: Social contexts, theories, and systems (pp. 176-197). New York: Cambridge University Press.

White, R.W. (1974) Strategies of adaptation: An attempt at systematic description. In G. Coehlo, D.Hamburg \& J. Adams (Eds) Coping and adaptation (pp 47-68). New York: Basic Books.

Whitmarsh, L., O’Neill, S. \& Lorenzoni, I. (Eds) (2010) Engaging the public with climate change. London: Earthscan. 
Winkel, G., Saegert, S. \& Evans, G.W. (2010) An ecological perspective on theory, methods, and analysis in environmental psychology: Advances and challenges. Journal of Environmental Psychology, 29, 318-328.

Yeager, D.S., Larson, S.B. \& Krosnick, J. (2010) Measuring Americans’ issue priorities: A new version of the most important problem question reveals more concern about global warming and the environment. Palo Alto, CA: Stanford University, Woods Institute for the Environment. http:woods.stanford.edu/research/surveys.html. 
Direct, indirect \& mediated threats and impacts

Discrete (e.g., Cataclysmic) events

Chronic events including ambient stressors
Threat appraisal (aka primary or risk appraisals)

Assessing whether impacts on self, family, community, culture, and society exceed resources

- Perceived probability of risk

- Perceived severity

- Perceived vulnerability \& resilience

Coping appraisal (aka secondary appraisals)

Assessing anticipated effects of possible

responses and capacity to respond

Seli-efficacy

Response-efficacy

Cost-benefits

Situation constraints

Strength of community

Interpretive and

motivational responses

and processes

- Attributions

- Affective responses

- Motivational processes and Global Climate Change

Continuous \&

Dynamic Process

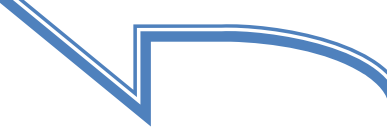

Proactive and reactive coping response

Intra-individual responses (examples)

vironmental numbness

cognitive reappraisal such as altering risk assessment emotion regulation

Behavioral responses (examples)

- seeking information

seeking interpersonal or community social support

compensatory behavior such as

changing structure of habitat

Mitigation

Civic participation
Psychosocial Impacts on Individuals and communities

Examples of Moderators of each step in the process

Characteristics of Individual Resilience and vulnerability

Prior experience

Dispositional optimist
Characteristics of incident

and physical environment

- Region specific biophysical impacts

- Proximity \& exposure to impacts
Characteristics of community$$
\text { Resilience and vulnerability }
$$

Social capital and social networks

Media representations, social construal \& reactions

Cultural norms

Neighborhood organizations

Figure 1: Psychological processes that influence adaptation and coping with climate change. 